\title{
Smilax glabra Rhizoma affects the pharmacokinetics and tissue distribution of methotrexate by increasing the P-glycoprotein mRNA expression in rats after oral administration
}

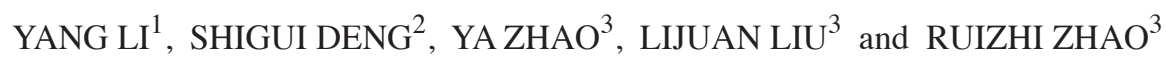 \\ ${ }^{1}$ Key Research Laboratory of Gynecology; ${ }^{2}$ Department of The Public Experiment Platform; \\ ${ }^{3}$ Department of Chinese Medicine Property Team, Department of Gynecology, Guangdong Provincial Hospital of \\ Chinese Medicine, The Second Affiliated Hospital, Guangzhou University of Chinese Medicine, \\ Guangzhou, Guangdong 510120, P.R. China
}

Received October 9, 2016; Accepted July 20, 2017

DOI: $10.3892 / \mathrm{mmr} .2017 .7559$

\begin{abstract}
Methotrexate (MTX) is a widely used immunosuppressant and anticancer agent with high toxicity. Smilax glabra Rhizoma (SGR) has the effect of detoxification and immunoregulation, and has been used as both food and folk medicine in many countries. Co-administration of MTX and SGR occurs in several diseases. However, whether they work synergistically or are incompatible remains unknown. In the present study, MTX was administrated to rats alone or combined with SGR. Blood and tissue samples were collected at designated times. The concentrations of MTX were determined by high-performance liquid chromatography. Reverse transcription-quantitative polymerase chain reaction (RT-qPCR) was used to detected the gene expression. SGR decreased the $\mathrm{AUC}_{0-\mathrm{t}}$ and $\mathrm{C}_{\max }$ of MTX by 44.5 and $48.2 \%$, but in a tissue-dependent manner. The total exposure of MTX was significantly decreased in the small intestine, stomach, plasma, and kidney by $61.6,34.7,63.3$ and $46.1 \%$, respectively, but was increased in the lung and spleen by 82.9 and $21.0 \%$, respectively. RT-qPCR demonstrated that SGR increased the mean P-glycoprotein (gp) mRNA expression in the small intestine 2.54 times, but had a marginal effect on the expression of organic anion transporting polypeptide 2, and organic anion transporter (OAT) 1 and OAT2. These results suggested that SGR affects the pharmacokinetics of MTX in
\end{abstract}

Correspondence to: Professor Ruizhi Zhao, Department of Chinese Medicine Property Team, Department of Gynecology, Guangdong Provincial Hospital of Chinese Medicine, The Second Affiliated Hospital, Guangzhou University of Chinese Medicine, 55 Neihuan West Road, Panyu, Guangzhou, Guangdong 510120, P.R. China E-mail: 13610241754@163.com

Key words: pharmacokinetics, Smilax glabra Rhizoma, methotrexate, P-glycoprotein, reverse transcription-quantitative polymerase chain reaction a tissue-dependent manner by affecting P-gp, and the clinical effect of co-administration depended on the disease site.

\section{Introduction}

Methotrexate (MTX), an antifolate and anticancer agent with a narrow therapeutic window, is commonly used for refractory rheumatoid arthritis, psoriasis, breast carcinoma, lung and liver cancer and systemic lupus erythematosus $(1,2)$. However, besides its affirmative effect in the clinic, MTX has many side effects including nausea, vomiting, mucositis, diarrhea, stomatitis, myelosuppression $(3,4)$ and hepatotoxicity (5). All these side effects limit its use, and the toxicity is so severe that $>50 \%$ patients give up the treatment (6).

Currently, methods such as folic acid supplementation for reducing the dosage and regularly checking the body functions are a clinical way to reduce the side effects of MTX. However, the remedial method of detoxification after MTX poisoning does not tend to be effective. Therefore, ethnomedicines may be of importance, particularly if they have detoxifying effects. For example, one of the most commonly used detoxicants is Smilax glabra Rhizoma (SGR; Tufuling in Chinese).

SGR is a natural dietary supplement widely used in food-making and health care in Southeast Asia, Arabian countries and North America (7,8). Various bioactivities of SGR have been demonstrated in in vitro and in vivo assays, including anti-cancer (9), antiviral (10), anti-inflammatory (11), immunomodulatory (12), detoxification and hepatoprotective effects (13). In the clinic, patients with rheumatoid arthritis, cancer, nephroma and even MTX-induced hepatotoxicity (14-16), receive treatment with a combination of MTX and SGR or SGR-containing herbal mixtures frequently $(17,18)$.

Investigating the drug-drug interaction (DDI) or drug-herb interaction (DHI) using pharmacokinetic methods has become popular. DDI or DHI are usually induced by drug metabolism enzyme or drug transporters. MTX enters cells primarily by carrier-mediated uptake $(19,20)$. Therefore, DDI or DHI induced by MTX may mainly associate with drug transporters. MTX is the substrate of P-glyocoprotein (gp) (21), multidrug-resistance-associated protein (MRP)1, 2 and 3 (22-25), 
and organic anion transporters (OAT)1, $2(26,27)$. Anything which could change the activity of the above transporters may induce DDI or DHI of MTX.

Astilbin is the major active component of SGR, and the content in SGR usually $>0.4 \%$. Wang et al (28) reported that astilbin increased the expression of P-gp in rats. In vivo, astilbin are further metabolized into sulfates and glucuronides (29), which all are the substrate of MRP1, MRP2, and MRP3 (30-32). This indicates that DHI may happen with a combination of MTX and SGR, but this interaction requires further study.

Therefore, in the present study, the effect of SGR on the pharmacokinetics and tissue distribution of MTX was studied in rats, and the potential underlying mechanism was investigated.

\section{Materials and methods}

Chemicals and reagents. MTX was purchased from Guangzhou Lubex Biological Technology Co., Ltd. (Guangdong, China; batch no. 100138-201104). SGR was purchased from Kangmei Pharmaceutical Co., Ltd., (Guangdong, China) in February 2013 (batch no. 130800051) and was verified by Chen Wen-liang in the Second Affiliated Hospital, Guangzhou University of Chinese Medicine (Guangzhou, China). SPE cartridges were supplied by Dikma Technologies, Inc. (Beijing, China). All other materials were analytical grade or better and used as received.

Preparation of SGR decoction. Ethanol (75\%) was added to $450 \mathrm{~g}$ crude drug, soaked for $30 \mathrm{~min}$ and then heated on a reflux extraction device. After boiling, gentle heating was continued for $1 \mathrm{~h}$, the mixture was filtered, and the filtrate was concentrated by rotary evaporators. The volume was kept to $150 \mathrm{ml}$ and frozen at $-20^{\circ} \mathrm{C}$ for later use. The chromatographic fingerprint of SGR has been analyzed in our previous study (33). The concentration of astilbin in the extract was $\sim 0.48 \%$.

Animal and drug administration. A total of 54 male Sprague-Dawley (SD) rats aged 7-8 weeks, weighing 300 $\pm 50 \mathrm{~g}$, were supplied by Southern Medical University (Guangzhou, China; certification no. 44002100003362). The rats were housed in cages at $21 \pm 3^{\circ} \mathrm{C}$ and $50 \%$ relative humidity on a 12 -h light/dark cycle. They were acclimated to this environment for 7 days with standard diet until the night prior to the experiment. The rats were then fasted overnight with free access to water. The studies were approved by the Animal Ethics Committee of Guangzhou University of Chinese Medicine (Guangzhou, China), and conducted in strict accordance with the recommendations in the guide for the care and use of Laboratory Animals of the National Institutes of Health (Bethesda, MA, USA).

Pharmacokinetic study. Pharmacokinetic studies were carried out in SD rats. Animals were randomly divided into two groups ( $\mathrm{n}=6$ per group). MTX was diluted with deionized water to obtain concentration of $0.6 \mathrm{mg} / \mathrm{ml}$. MTX $(6.0 \mathrm{mg} / \mathrm{kg})$ was given orally to rats with and without a concomitant oral dose of SGR (30 g/ $\mathrm{kg}$ of crude drugs) at $5 \mathrm{~min}$ before. Blood samples $(0.6 \mathrm{ml})$ were collected from orbit venous plexus into heparinized $1.5 \mathrm{ml}$ polythene tubes at predetermined time points $(10,20,40,60,120,240,360,480$ and $540 \mathrm{~min})$. The samples were immediately centrifuged at $3,500 \mathrm{xg}$ for $15 \mathrm{~min}$ at room temperature, and the supernatant was gathered as plasma and stored at $-80^{\circ} \mathrm{C}$ until analysis.

Tissues distribution study. Tissue distribution studies were carried out in 36 male SD rats. Animals were randomly divided into two groups ( $\mathrm{n}=18$ per group): MTX alone and MTX combined with SGR. MTX $(6.0 \mathrm{mg} / \mathrm{kg})$ was given orally to rats with and without a concomitant oral dose of SGR (30 g/ $/ \mathrm{kg}$ of crude drug) at 5 min beforehand. Following intragastric administration, rats were anesthetized by $10 \%$ chloral hydrate ( $4 \mathrm{ml} / \mathrm{kg}$; Tianjin Damao Chemical Reagent Factory, Tianjin, China) and sacrificed at predetermined time points $(20,60$ and $240 \mathrm{~min} ; 6$ rats were sacrificed at each time point of each group). Blood samples were obtained from the abdominal aorta; the chest and abdominal cavity were opened and tissues of interest (heart, liver, spleen, kidney, lung, stomach, intestine and marrow) were harvested and rinsed with ice-cold $0.9 \%$ $\mathrm{NaCl}$ to remove the superficial blood. Following being blotted dry with filter paper, the tissue samples were stored at $-80^{\circ} \mathrm{C}$ until analysis.

Sample preparation. The plasma was thawed and swirled for $10 \mathrm{sec}$, and then $100 \mu \mathrm{l}$ plasma was added to a pre-conditioned SPE column. After washing with $1 \mathrm{ml}$ deionized water, $1 \mathrm{ml}$ washing solution $[0.2 \%$ methanoic acid- methanol $(\mathrm{v} / \mathrm{v})]$ was used. The deionized water elution was discarded and washing solution elution was collected, then evaporated to dryness under a stream of nitrogen at $40^{\circ} \mathrm{C}$. The residue was re-dissolved with $100 \mu \mathrm{l}$ mobile phase and then filtered through a $0.22-\mu \mathrm{m}$ disposable syringe filter, of which $10 \mu \mathrm{l}$ was injected into the high-performance liquid chromatography (HPLC) system for analysis. Each tissue sample weight $\sim 300 \mathrm{mg}$ after thawing, and was homogenated in $0.9 \% \mathrm{NaCl}[1: 6(\mathrm{w} / \mathrm{v})]$. Tissue homogenate samples were centrifuged at 3,500 $\mathrm{xg}$ for $15 \mathrm{~min}$ at $4^{\circ} \mathrm{C}$, the supernatant was collected and conducted as plasma sample, and $10 \mu \mathrm{l}$ supernatant was used for HPLC analysis.

HPLC analysis. The chromatographic analysis was performed on an Agilent 1200 system (Agilent Technologies, Inc., Santa Clara, CA, USA) with a VWD detector at $302 \mathrm{~nm}$. Samples were analyzed on a Diamonsil C18 column $(250 \times 4.6 \mathrm{~mm}$ I.D, $5 \mu \mathrm{m}$; Dikma Technologies Inc.) at $30^{\circ} \mathrm{C}$. The mobile phase consisted of $0.1 \%$ formic acid aqueous solution (A) and methanol (B), using a gradient elution (0 min: $10 \% \mathrm{~B}, 8 \mathrm{~min}$ : $60 \% \mathrm{~B}, 10 \mathrm{~min}: 100 \% \mathrm{~B}$ ) at a flow rate of $1.0 \mathrm{ml} / \mathrm{min}$, and the injection volume was $10 \mu \mathrm{l}$.

Preparation of standard solution and quality control samples. Standard solution of MTX was prepared by using $0.1 \%$ formic acid water containing $5 \%$ methanol; the working concentration was $200 \mathrm{mg} / \mathrm{l}$. This was stored at $4^{\circ} \mathrm{C}$ in a dark place until use. Appropriate amounts of the standard solution were added to $100 \mu \mathrm{l}$ blank rat plasma or tissue homogenates to prepare the calibration standards of MTX, the final calibration standard concentrations were $0.052,0.104,0.157,0.313,0.626$, $1.252,2.503$ and $5.006 \mathrm{mg} / \mathrm{l}$ for plasma samples and 0.020 , 
Table I. Primer sequences used in reverse transcription-quantitative polymerase chain reaction.

\begin{tabular}{lll}
\hline Gene & \multicolumn{1}{c}{ Forward primer $\left(5^{\prime}-3^{\prime}\right)$} & \multicolumn{1}{c}{ Reverse primer $\left(5^{\prime}-3^{\prime}\right)$} \\
\hline Rat-P-gp & ATGAAACTGCCCCACAAATT & CTTTCTGTGTCCAAGGCTGA \\
Rat-OAT1 & CCATGCTGTGGTTTGCCACTA & ACAAACTTGGCAGGCAGGTC \\
Rat-OAT2 & TGGCCTATGCCATTCCAGAC & GGGATTCTGGGACAAACCAGT \\
Rat-GAPDH & ATGATTCTACCCACGGCAAG & CTGGAAGATGGTGATGGGTT \\
Rat-MRP1 & AGGTTGGTATTGTGGGTCGTA & GATGGTGATCTTGAAGCGCAGGTT \\
Rat-MRP2 & GGGACTCCAACCTGACTGTAT & CCTCTGGGCAAGGATTTGT \\
Rat-MRP3 & TCAGCATCCTCATCAGGTTTATT & ATGATAGCAGTCCGTATCCTCAA
\end{tabular}

$0.039,0.078,0.156,0.3125,0.625,1.25,2.5$ and $5 \mathrm{mg} / 1$ for tissue samples. Quality control (QC) samples were prepared at the lower limit of quantification (LLOQ); low, medium and high concentrations of $0.052,0.313,1.252$ and $5.006 \mathrm{mg} / \mathrm{l}$ for plasma samples and $0.020,0.078,0.3125$ and $1.25 \mathrm{mg} / \mathrm{l}$ for tissue samples.

Method validation. The specificity of the assay was assessed by comparing the chromatograms of blank sample with the corresponding spiked samples, and each blank sample was tested to ensure that it had no interference on the elution of MTX. The calibration curves were constructed from the peak area of each standard solution against homographic concentrations using eight-level nonzero standards and a linearly weighed $(1 / x)$ least squares regression model. The accuracy and precision were determined by replicate analysis $(n=6)$ of QC samples on three different time points. Relative standard deviation (RSD)\% was used to evaluate the accuracy and the intra- and inter-day precision. The extract recovery of MTX at QC levels were evaluated by assaying the samples as described above and comparing peak areas with those obtained from the compounds dissolved in the supernatant of the processed blank plasma. The stability of plasma and tissues was investigated by analyzing of the samples at QC levels $(n=6)$ under different conditions.

Reverse transcription-quantitative polymerase chain reaction $(R T-q P C R)$. Tissues were homogenized in RNAiso Plus (Sigma-Aldrich; Merck KGaA, Darmstadt, Germany) to extract total RNA according to the manufacturer's protocol. The quality and concentration of RNA were determined using the OD260/280 ratio measured by the Thermo NanoDrop 2000c (Thermo Fisher Scientific, Inc., Waltham, MA, USA) and stored at $-80^{\circ} \mathrm{C}$ prior to use. cDNA was synthesized from total RNA ( $1 \mu \mathrm{g} ; 20 \mu \mathrm{l}$ final reaction volume) with oligo(dT) priming using M-MLV platinum Green qPCR Super Mix-UDG (Invitrogen; Thermo Fisher Scientific, Inc.) according to the manufacturer's protocol, then performed on Veriti 96 Well Thermal Cycler (Applied Biosystems; Thermo Fisher Scientific, Inc.).

qPCR was performed on an ABI Prism TM 7500 Real Time qPCR system (Applied Biosystems; Thermo Fisher Scientific, Inc.) using the SYBR Select Mastermix (Applied Biosystems; Thermo Fisher Scientific, Inc.). The experiment was carried out using optical 96-well reaction plates covered with plate sealers. Samples were treated following the instructions of SYBR Select Mastermix (Applied Biosystems; Thermo Fisher Scientific, Inc.): Each tube of reaction mix consisted of $2 \mu \mathrm{l}$ of RT cDNA, forward and reverse primers (each $0.4 \mu \mathrm{l}$ ), $10 \mu \mathrm{l}$ SYBR Select Mastermix and $7.2 \mu 1$ no enzyme water (20 $\mu 1$ final reaction volume). Primer sequences used for RT-qPCR are listed in Table I. Cycling parameters were as follows: $50^{\circ} \mathrm{C}$ for $2 \mathrm{~min}, 95^{\circ} \mathrm{C}$ for $1 \mathrm{~min}$, then 40 cycles of $95^{\circ} \mathrm{C}$ for $15 \mathrm{sec}$ and $60^{\circ} \mathrm{C}$ for 1 min. A melting temperature-determining dissociation step was performed at $96^{\circ} \mathrm{C}$ for $15 \mathrm{sec}, 60^{\circ} \mathrm{C}$ for $1 \mathrm{~min}$, and $95^{\circ} \mathrm{C}$ for $15 \mathrm{sec}$, for a total of 45 cycles in a procedure.

The data were analyzed by the comparative $\mathrm{Cq}$ method (34). $\mathrm{Cq}$ was recorded for the expression of each gene assayed in the RT-qPCR. All the Cq values were means of triplicate samples tested. GAPDH was chosen as the reference gene for the internal control. Differences between the $\mathrm{Cq}$ values of the target gene and the internal control gene $(\Delta \mathrm{Cq}=\mathrm{Cq}$ target $-\mathrm{Cq}$ internal control) were calculated to normalize the differences. Differences between $\Delta \mathrm{Cq}$ of each sample and calibrator $\Delta \Delta \mathrm{Cq}=\left(\mathrm{Cq}_{\text {calibrator }}-\Delta \mathrm{Cq}\right)$ were calculated. The change in the gene expression was calculated as $2^{-\Delta \Delta \mathrm{Cq}}$.

Statistical analysis. DAS software version 2.0 (DAS for eCDM; Shanghai University of Traditional Chinese Medicine, Shanghai, China) was used to calculate the pharmacokinetic parameters by non-compartmental model. Concentrations below the lower limit of quantify were treated as 0 . Data analysis was performed using SPSS version 19.0 software (IBM Corp., Armonk, NY, USA). One-way analysis of variance was used for multiple comparisons, and post hoc testing was performed using Tukey if necessary, or comparisons between two groups were made using Student's t-test. Data are expressed as the mean \pm standard deviation and mean \pm standard error of the mean. $\mathrm{P}<0.05$ was considered to indicate a statistically significant difference.

\section{Results}

Method validation (Tables II and III). No endogenous interference was observed at retention times of MTX. The calibration curves were linear over the concentration range of $0.052-5.006 \mathrm{mg} / 1$ with correlation coefficients of 0.9983 for plasma samples and 0.020-5.000 $\mathrm{mg} / \mathrm{l}$ for tissue samples, with correlation coefficients over 0.9981 . RSD in rat plasma and tissues were measured to be ranged between 2.3-6.3\% for intra-day precision, and 3.1-9.4\% for inter-day precision. 
Table II. The lineal regression analysis of MTX in rat plasma and tissues.

\begin{tabular}{lcc}
\hline Sample & Calibration curves & $r$ \\
\hline Plasma & $\mathrm{Y}=21.621, \mathrm{X}-0.0793$ & 0.9983 \\
Heart & $\mathrm{Y}=33.026, \mathrm{X}+0.3935$ & 0.9981 \\
Liver & $\mathrm{Y}=28.034, \mathrm{X}-0.0175$ & 0.9992 \\
Spleen & $\mathrm{Y}=23.367, \mathrm{X}+0.1808$ & 0.9989 \\
Lungs & $\mathrm{Y}=28.265, \mathrm{X}+0.3864$ & 0.9985 \\
Kidney & $\mathrm{Y}=31.839, \mathrm{X}+0.5685$ & 0.9971 \\
Marrow & $\mathrm{Y}=23.288, \mathrm{X}+0.2463$ & 0.9917 \\
Small intestine & $\mathrm{Y}=27.456, \mathrm{X}+0.6947$ & 0.9990 \\
Stomach & $\mathrm{Y}=21.621, \mathrm{X}-0.0793$ & 0.9978 \\
\hline
\end{tabular}

MTX, methotrexate.

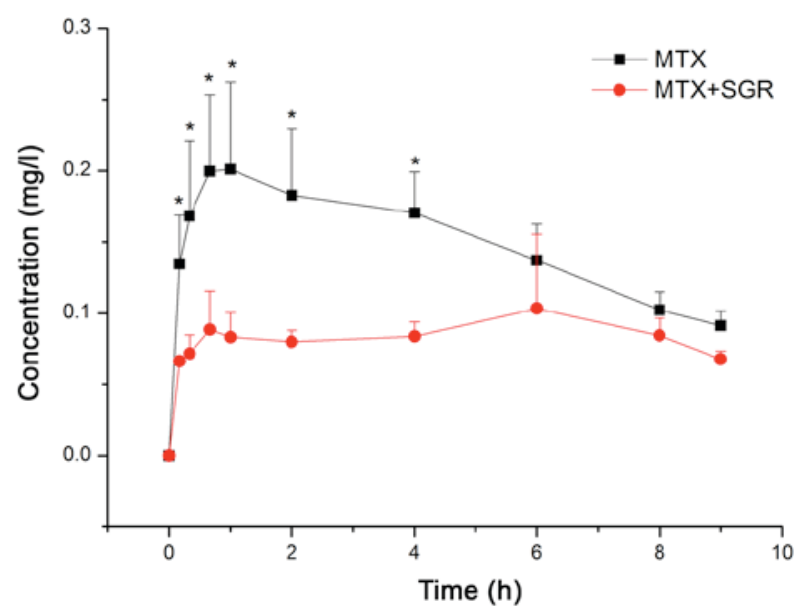

Figure 1. Mean plasma concentration-time curve of MTX treatment alone or combined with SGR, after oral administration to rats. Data are presented as the mean \pm standard deviation ( $\mathrm{n}=6$ per group). ${ }^{*} \mathrm{P}<0.05$ compared with MTX+SGR group at each time point. MTX, methotrexate; SGR, Smilax glabra Rhizoma.

The accuracy obtained was between 87.3 and $109.8 \%$ with $\mathrm{RSD}<8.6 \%$. The extraction recoveries of MTX in plasma and various tissues were ranged from $77-102 \%$ with RSD $<8.1 \%$. Stability study demonstrated that after $24 \mathrm{~h}$ at room temperature, three freeze-thaw cycles and 2 weeks of storage, the sample was stable and the RSD were within 9.8\%.

SGR affects the pharmacokinetics of MTX significantly. The pharmacokinetics of mean concentration-time curves of MTX are presented in Fig. 1. In general, the maximal MTX concentration in serum occurred in $1 \mathrm{~h}$ and then gradually decreased to below detectable levels. This is consistent with previous studies $(35,36)$. The plasma concentration profiles of MTX demonstrated nonlinear pharmacokinetics. The corresponding pharmacokinetic parameters are listed as the mean \pm standard deviation and presented in Table IV. When co-administrated with SGR, MTX demonstrated a much lower concentration than when used alone. The $\mathrm{C}_{\max }$ was significantly decreased by $44.5 \%$ and the $\mathrm{T}_{1 / 2}, \mathrm{~T}_{\max }$ were significantly prolonged by 92.8 and $398.9 \%$, respectively. Although SGR significantly

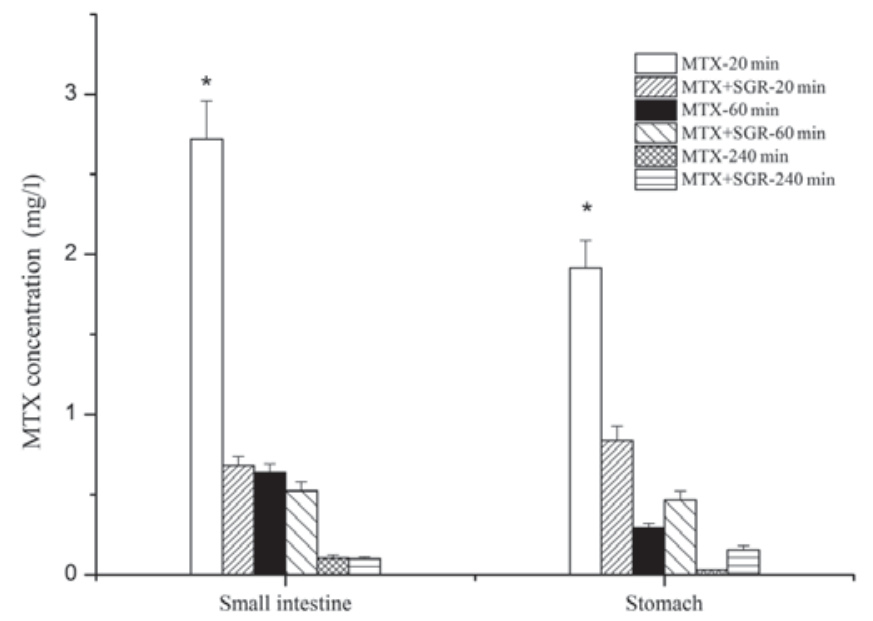

Figure 2. Mean concentration of MTX in the stomach and small intestine at 20,60 and $240 \mathrm{~min}$ after oral administration to rats. Data are presented as the mean \pm standard error ( $\mathrm{n}=6$ per group). ${ }^{*} \mathrm{P}<0.05$ compared with MTX+SGR group at $20 \mathrm{~min}$. MTX, methotrexate; SGR, Smilax glabra Rhizoma.

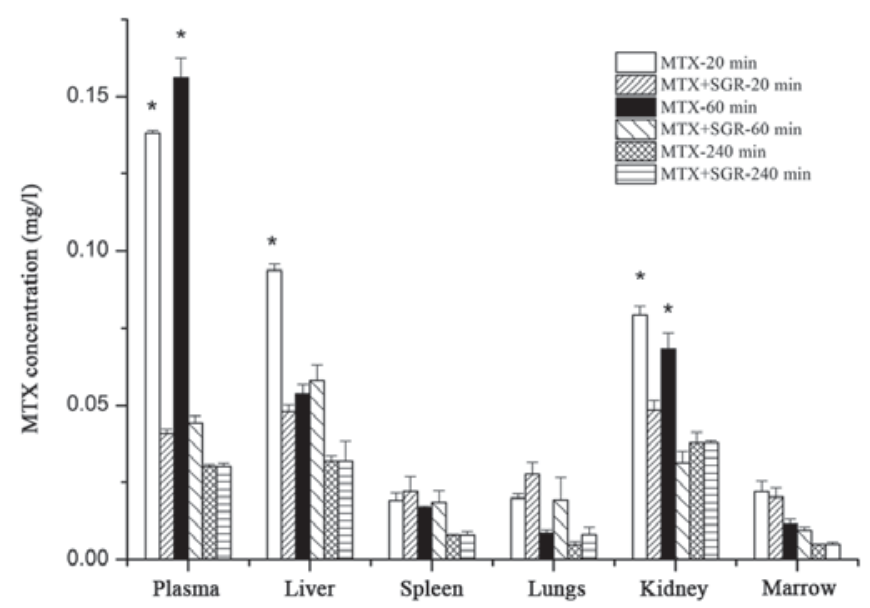

Figure 3. Mean concentration of MTX in the plasma, liver, kidney, lung, spleen and marrow tissues at 20, 60 and $240 \mathrm{~min}$ after oral administration to rats. Data are presented as the mean \pm standard error. ${ }^{*} \mathrm{P}<0.05$ compared with MTX+SGR group at each time point. MTX, methotrexate; SGR, Smilax glabra Rhizoma.

decreased $\mathrm{AUC}_{0-\mathrm{t}}$ of MTX $(\mathrm{P}<0.001)$, it still had marginal effect on $\mathrm{AUC}_{0-\infty}$, demonstrating an elimination inhibiting effect. The concentration-time profile of MTX in the combination group remained level, and very similar to the profile of sustained release pharmaceuticals, in which the flat profile is as a result of continuous slow absorption. Concentration levels peaked at $6 \mathrm{~h}$, indicating that there may be circulation between the gut and liver (Fig. 1).

SGR affects tissue distribution of MTX with a tissue dependent manner. The concentration of MTX in tissue homogenate at 20,60 and $240 \mathrm{~min}$ after oral administration are presented in Figs. 2 and 3. When MTX was used alone, the $\mathrm{C}_{\max }$ in majority tissues were $20 \mathrm{~min}$, indicating that MTX underwent a rapid and wide distribution from blood to tissues, and this is in accordance with its wide curative effect to different diseases. The highest concentration of MTX was observed in the small intestine and stomach 
Table III. The accuracy, precision, recovery, and stability of cisplatin in nude mouse plasma and tissues samples (\%, mean \pm standard deviation, $\mathrm{n}=6$ per group).

\begin{tabular}{|c|c|c|c|c|c|c|c|c|}
\hline \multirow[b]{2}{*}{ Sample } & \multirow[b]{2}{*}{ Level ng/ml } & \multirow[b]{2}{*}{ Accuracy $\%$} & \multicolumn{2}{|c|}{ Precision (RSD \%) } & \multirow[b]{2}{*}{ Recovery \% } & \multicolumn{3}{|c|}{ Stability \% } \\
\hline & & & Intraday & Interday & & Short term & Long term & Freeze-thaw \\
\hline \multirow[t]{4}{*}{ Plasma } & 0.052 & 87.5 & 5.3 & 9.4 & $78.6 \pm 4.3$ & 2.3 & 6.7 & 2.9 \\
\hline & 0.313 & 88.9 & 4.2 & 5.9 & $79.9 \pm 5.9$ & 3.6 & 2.9 & 4.8 \\
\hline & 1.252 & 91.6 & 5.5 & 4.4 & $91.0 \pm 8.1$ & 1.6 & 3.3 & 7.6 \\
\hline & 5.006 & 89.5 & 6.2 & 3.7 & $82.9 \pm 6.3$ & 2.6 & 4.6 & 3.5 \\
\hline \multirow[t]{4}{*}{ Marrow } & 0.020 & 88.0 & 2.5 & 4.7 & $91.3 \pm 0.9$ & 1.3 & 3.4 & 4.9 \\
\hline & 0.078 & 89.1 & 2.3 & 5.1 & $97.2 \pm 7.6$ & 4.1 & 3.9 & 4.3 \\
\hline & 0.313 & 88.3 & 4.6 & 6.8 & $83.1 \pm 8.5$ & 1.9 & 3.9 & 5.2 \\
\hline & 1.252 & 92.9 & 1.2 & 3.9 & $93.9 \pm 5.9$ & 2.6 & 5.6 & 4.3 \\
\hline \multirow[t]{4}{*}{ Liver } & 0.020 & 87.3 & 4.3 & 9.4 & $78.7 \pm 9.1$ & 1.3 & 6.9 & 7.9 \\
\hline & 0.078 & 88.6 & 4.9 & 6.4 & $97.4 \pm 7.2$ & 2.1 & 3.1 & 3.8 \\
\hline & 0.313 & 98.1 & 3.8 & 5.8 & $96.8 \pm 0.9$ & 3.6 & 4.1 & 7.1 \\
\hline & 1.252 & 105.9 & 2.5 & 4.9 & $91.6 \pm 4.1$ & 1.7 & 4.5 & 4.5 \\
\hline \multirow[t]{4}{*}{ Spleen } & 0.020 & 88.5 & 5.6 & 6.8 & $87.1 \pm 4.3$ & 0.9 & 6.8 & 3.2 \\
\hline & 0.078 & 91.7 & 5.1 & 9.3 & $81.8 \pm 4.7$ & 3.6 & 6.6 & 4.1 \\
\hline & 0.313 & 97.8 & 4.8 & 5.2 & $95.8 \pm 1.5$ & 3.4 & 7.3 & 4.6 \\
\hline & 1.252 & 102.3 & 3.2 & 6.8 & $101.6 \pm 7.5$ & 4.1 & 8.2 & 6.5 \\
\hline \multirow[t]{4}{*}{ Lung } & 0.020 & 92.6 & 5.8 & 7.9 & $79.4 \pm 5.6$ & 4.3 & 8.9 & 2.1 \\
\hline & 0.078 & 94.3 & 5.3 & 9.2 & $99.7 \pm 8.5$ & 3.8 & 7.6 & 3.8 \\
\hline & 0.313 & 108.3 & 4.1 & 6.6 & $98.0 \pm 5.7$ & 2.7 & 4.3 & 5.6 \\
\hline & 1.252 & 97.7 & 3.8 & 4.4 & $102.3 \pm 0.9$ & 2.9 & 4.3 & 3.7 \\
\hline \multirow[t]{4}{*}{ Kidney } & 0.020 & 100.1 & 4.1 & 6.4 & $88.4 \pm 5.7$ & 2.8 & 4.7 & 2.3 \\
\hline & 0.078 & 98.5 & 5.8 & 4.3 & $80.2 \pm 6.8$ & 1.6 & 9.8 & 4.7 \\
\hline & 0.313 & 101.5 & 3.4 & 3.8 & $85.4 \pm 0.8$ & 0.9 & 9.3 & 5.6 \\
\hline & 1.252 & 109.8 & 2.7 & 3.5 & $86.8 \pm 1.6$ & 1.6 & 5.1 & 3.9 \\
\hline \multirow[t]{4}{*}{ Small intestine } & 0.020 & 89.3 & 2.6 & 5.7 & $80.0 \pm 6.9$ & 4.1 & 9.1 & 2.5 \\
\hline & 0.078 & 90.3 & 3.8 & 4.9 & $89.5 \pm 4.4$ & 7.1 & 6.9 & 6.1 \\
\hline & 0.313 & 101.6 & 5.9 & 4.5 & $94.4 \pm 3.2$ & 3.4 & 3.4 & 5.1 \\
\hline & 1.252 & 105.7 & 3.5 & 6.6 & $101.8 \pm 7.4$ & 5.8 & 4.4 & 3.9 \\
\hline \multirow[t]{4}{*}{ Stomach } & 0.020 & 87.9 & 2.9 & 7.6 & $101.0 \pm 2.7$ & 2.3 & 7.1 & 2.5 \\
\hline & 0.078 & 101.8 & 5.3 & 6.6 & $88.9 .5 \pm 2.4$ & 4.4 & 3.5 & 3.6 \\
\hline & 0.313 & 103.7 & 4.2 & 3.9 & $95.4 \pm 4.9$ & 5.0 & 7.8 & 6.5 \\
\hline & 1.252 & 104.3 & 5.1 & 4.2 & $96.8 \pm 6.1$ & 6.6 & 6.3 & 7.3 \\
\hline
\end{tabular}

(Fig. 2), followed by the plasma, liver, and kidney (Fig. 3). MTX concentrations were relatively low in the lung, spleen and marrow (Fig. 3), and the concentration of MTX in the heart was too low to test, which is roughly consistent with previous studies $(37,38)$.

When co-administered with SGR, the concentration of MTX in tissues changed in a tissue- and time-dependent manner. Although the $\mathrm{T}_{\max }$ was at $20 \mathrm{~min}$, the $\mathrm{C}_{\max }$ decreased significantly compared with MTX used alone. $\mathrm{C}_{\max }$ in the small intestine, stomach, plasma, liver and kidney were decreased by $74.9,56.2,70.4,48.9$ and $40.0 \%$, respectively, at $20 \mathrm{~min}$. Following that, the effect of SGR seemed to weaken; at the 1-h time point, SGR decreased the concentration of MTX in the plasma and kidney markedly, but increased the concentration of MTX in the stomach and lung; no obvious differences of MTX concentration were observed between the two groups at $240 \mathrm{~min}$. This indicated a much slower elimination in most tissues when combined with SGR, and which is accorded with the pharmacokinetic study.

On the whole, the total exposure of MTX was also significantly reduced in the small intestine, stomach, plasma and kidney by $61.6,34.7,63.3$ and $46.1 \%$, respectively. Notably, the total exposure of MTX in the lung and spleen were increased by 82.9 and $21.0 \%$, respectively. However, was no obvious change was observed in the marrow.

SGR enhances $P$-gp gene expression in intestine but has a marginal effect on other transporters. As the effect of SGR on the in vivo behavior of MTX mainly focused on absorption and excretion, the gene expression of transporters which all transport MTX such as P-gp, MRP3, organic anion transporting polypeptide (OATP2), MRP2 in the intestine and P-gp, 
Table IV. Pharmacokinetic parameters of MTX in rats orally administered MTX alone and in combination with SGR $(n=6$ per group).

\begin{tabular}{lcc}
\hline Parameters & \multicolumn{2}{c}{ MTXMTX + SGR } \\
\hline $\mathrm{AUC}_{0-\mathrm{-}} / \mathrm{mg} / \mathrm{h} / \mathrm{l}$ & $1.353 \pm 0.169$ & $0.751 \pm 0.163^{\mathrm{c}}$ \\
$\mathrm{AUC}_{0-\infty} / \mathrm{mg} / \mathrm{h} / \mathrm{l}$ & $2.698 \pm 0.403$ & $2.871 \pm 1.488$ \\
$\mathrm{MRT}_{0-\mathrm{l}} / \mathrm{h}$ & $4.008 \pm 0.309$ & $4.551 \pm 0.274$ \\
$\mathrm{~T}_{1 / 2} / \mathrm{h}$ & $9.884 \pm 3.283$ & $19.058 \pm 10.616^{\mathrm{a}}$ \\
$\mathrm{C}_{\max } / \mathrm{mg} / \mathrm{l}$ & $0.218 \pm 0.059$ & $0.113 \pm 0.047^{\mathrm{b}}$ \\
$\mathrm{CL} / \mathrm{L} / \mathrm{h} / \mathrm{kg}$ & $2.271 \pm 0.370$ & $2.663 \pm 1.440$ \\
$\mathrm{~T}_{\text {max }} / \mathrm{h}$ & $0.902 \pm 0.683$ & $4.5 \pm 2.665^{\mathrm{a}}$ \\
\hline
\end{tabular}

Data are expressed as the mean \pm standard deviation. ${ }^{\mathrm{a}} \mathrm{P}<0.05$, ${ }^{\mathrm{b}} \mathrm{P}<0.01,{ }^{\mathrm{c}} \mathrm{P}<0.001$ vs. MTX. MTX, methotrexate; SGR, Smilax glabra Rhizoma; $\mathrm{T}_{\max }$, time of peak serum level; $\mathrm{C}_{\max }$, concentration of peak serum level; $\mathrm{T}_{1 / 2}$, elimination half-life; $\mathrm{AUC}_{0-\mathrm{t}}$, area under serum concentration-time curve to the last point; $\mathrm{CL} / \mathrm{L}$, clearance over absolute bioavailability; $\mathrm{MRT}_{0-\mathrm{t}}$, mean residence time.

OAT1, OAT2, MRP1 and MRP2 in the kidney, were studied. The results are presented in Figs. 4 and 5.

The effect of SGR on gene expression demonstrated a time-, transporter- and tissue-dependent manner. SGR increased P-gp mRNA expression in the small intestine by 2.54 times $(\mathrm{P}<0.05)$ at both 20 and 60 min time points, but had marginal effects on the gene expression of OATP2, MRP2 and MRP3 in the intestine at all the time points (Fig. 4), indicating that upregulation of P-gp expression is the main effect of SGR-induced MTX absorption decreasing. However, different from the results in intestine, SGR had a marginal effect on P-gp, OAT1 and OAT2 expression in the kidney, but increased the expression of MRP2 and MRP3. The result is coincidence with the concentration decreasing of MTX in kidney (Fig. 5). This indicated that SGR prolonged the retention time of MTX in plasma by increasing the expression of MRP1 and MRP2. This may be one of the reasons of the flat profile and low elimination rate of MTX in plasma.

\section{Discussion}

SGR was originally recorded by 'Diannan Materia Medica' in the Ming Dynasty of China (1368-1644), and officially listed in the Chinese Pharmacopeia (2015 edition) (39). The stipulated prescription dose is $15-60 \mathrm{~g}$, and when SGR is generally consumed in tea or soup, the dosage often exceeds the prescribed dose. MTX and SGR are frequently used combination in the clinic; however, the benefits remain unclear (40). To the best of our knowledge, the present study was the first to examine the in vivo effects of SGR on the fate of MTX, and the results demonstrated that SGR affected the absorption, distribution and elimination significantly, and may induce significant DHI.

Drug concentration in plasma is significantly reduced in the intestines, stomach, liver and kidney, and it was hypothesized that SGR may affect the MTX treatment effect when used in the treatment of psoriasis, digestive tract cancer and systemic lupus erythematosus. Additionally, when patients

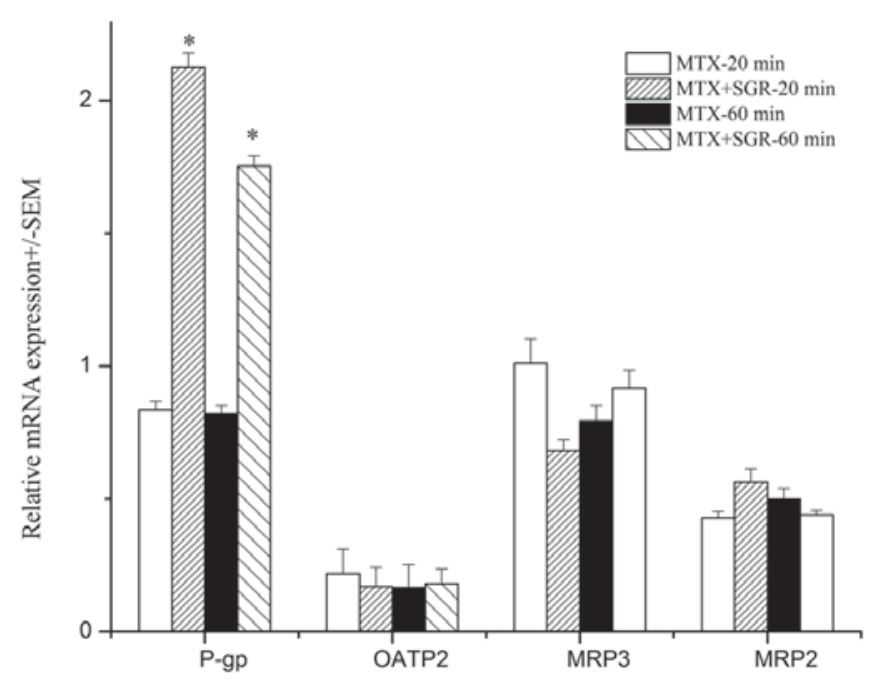

Figure 4. Relative gene expression of P-gp, OATP2, MRP3 and MRP2 in the small intestine at 20 and $60 \mathrm{~min}$. Data are presented as the mean \pm standard error. "P $<0.05$ compared with MTX alone at each time point. MTX, methotrexate; SGR, Smilax glabra Rhizoma; P-gp, P-glyocoprotein; OATP2, organic anion transporting polypeptide; MRP, multidrug resistance-associated protein.

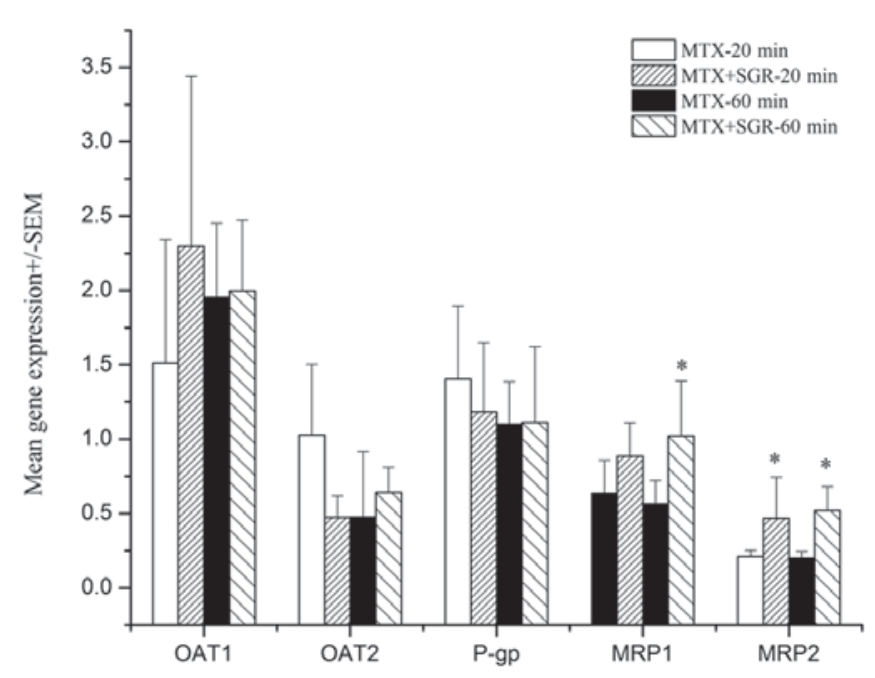

Figure 5. Relative gene expression of OAT1, OAT2, P-gp, MRP1 and MRP2 in the kidney at 20 and $60 \mathrm{~min}$. Data are presented as the mean \pm standard error. ${ }^{*} \mathrm{P}<0.05$ compared with MTX alone at each time point. MTX, methotrexate; SGR, Smilax glabra Rhizoma; P-gp, P-glyocoprotein; MRP, multidrug resistance-associated protein; OAT, organic ion transporter.

are receiving MTX therapy and taking SGR at the same time, it is suggested that the dosing interval should be extended to prevent unnecessary toxic effect, due to the significant inhibition of the elimination of MTX by SGR.

In the present study, although SGR significantly decreased the concentration of MTX in most tissues, its concentration in the lung, spleen and marrow were not reduced; it increased the drug concentration of MTX in lung and spleen significantly. Therefore, in the treatment of various types of cancer, such splenic carcinoma, osteosarcoma, acute leucocythemia, malignant lymphoma and multiple myeloma (41), MTX co-administration with SGR may be helpful to enhance its tumoricidal effect while decreasing the toxicity such as nausea, vomiting, diarrhea and stomatitis. 
MTX is the substrate of many transporters, as previously described. The efficacy and toxicity of MTX may be changed drugs used in combination affect transporter activity (42). Transporters have different expression levels in different tissues, and our previous study demonstrated that the effect of drugs on the activity of transporters depends on the protein amount (data not shown) $(43,44)$. The RT-qPCR results indicated that SGR increased P-gp expression by 2.5 times in the intestine; thus, it was hypothesized that SGR-induced gene expression of P-gp may be the reason for MTX low absorption in intestine, and much lower $\mathrm{C}_{\max }$ in blood. This is consistent with a previous report that P-gp is associated with clinical responses to MTX $(45,46)$ On the other hand, in the present study, SGR increased the expression of MRP1 and MRP2 in the kidney, but had a marginal effect on P-gp. This may be because P-gp had much higher expression in the intestine than in the kidney, and vice versa. This may partially explain the flat profile of MTX concentration over time. Elimination of drugs from blood is the total effect of all tissues, so the mechanism requires further study.

In recent years, flavonoids-rich botanical products have been used as dietary supplements worldwide. However, their safety remains unanswered (47). Additionally, the pharmacokinetics of other acidic pharmaceuticals such as probenecid, ciprofloxacin and penicillin, which ware putative substrates of P-gp, may also be affected by concurrent use of SGR $(48,49)$ As the side effect of drugs raised concern, herbal treatment has attracted increasing attention, particularly a combination of herbs and drugs. Therefore, investigations into herb-drug interactions HDI are urgently required.

In conclusion, to the best of our knowledge, the present study demonstrated for the first time the potential benefits of co-administration of MTX with SGR. Co-administration of SGR may be beneficial for therapy of lung cancer and splenic carcinoma, osteosarcoma, and liver diseases, but may reduce the therapeutic effect of treating cancer in the digestive tract, systemic lupus erythematosus and psoriasis (50-54). The herb-drug interaction may be associated with the activity change of transporters.

\section{Acknowledgements}

The present study was supported by the Science and Technology Department Program of Guangdong Province of China (grant no. 2013B090700015), the Teamwork Project of Natural Science Foundation of Guangdong Province of China (grant no. S2013030011515) and the project of Traditional Chinese Medicine Hospital of Guangdong Province (grant nos. YK2013B1N11 and YN2014ZHR211).

\section{References}

1. Jolivet J, Cowan KH, Curt GA, Clendeninn NJ and Chabner BA The pharmacology and clinical use of methotrexate. N Engl J Med 309: 1094-1104, 1983.

2. Samarasekera E, Sawyer L, Parnham J and Smith CH; Guideline Development Group: Assessment and management of psoriasis: Summary of NICE guidance. BMJ 345: e6712, 2012.

3. Kuroda T, Namba K, Torimaru T, Kawashima K and Hayashi M: Species differences in oral bioavailability of methotrexate between rats and monkeys. Biol Pharm Bull 23: 334-338, 2000.

4. Carneiro-Filho BA, Lima IP, Araujo DH, Cavalcante MC, Carvalho GH, Brito GA, Lima V, Monteiro SM, Santos FN, Ribeiro RA and Lima AA: Intestinal barrier function and secretion in methotrexate-induced rat intestinal mucositis. Dig Dis Sci 49: 65-72, 2004
5. Duman DG, Kumral ZN, Ercan F, Deniz M, Can G and Cağlayan Yeğen B: Saccharomyces boulardii ameliorates clarithromycinand methotrexate-induced intestinal and hepatic injury in rats. Br J Nutr 110: 493-499, 2013.

6. Alarcón GS, Tracy IC and Blackburn WD Jr: Methotrexate in rheumatoid arthritis. Toxic effects as the major factor in limiting long-term treatment. Arthritis Rheum 32: 671-676, 1989.

7. Wang J, Li Q, Ivanochko G and Huang Y: Anticancer effect of extracts from a North American medicinal plant-wild sarsaparilla. Anticancer Res 26: 2157-2164, 2006.

8. Galhena PB, Samarakoon SR, Thabrew MI, Weerasinghe GA Thammitiyagodage MG, Ratnasooriya WD and Tennekoon KH: Anti-inflammatory activity is a possible mechanism by which the polyherbal formulation comprised of Nigella sativa (seeds), Hemidesmus indicus (root), and Smilax glabra (rhizome) mediates its antihepatocarcinogenic effects. Evid Based Complement Alternat Med 2012: 108626, 2012.

9. Gao Y, Su Y, Qu L, Xu S, Meng L, Cai SQ and Shou C: Mitochondrial apoptosis contributes to the anti-cancer effect of Smilax glabra Roxb. Toxicol Lett 207: 112-120, 2011.

10. Ooi LS, Sun SS, Wang H and Ooi VE: New mannose-binding lectin isolated from the rhizome of sarsaparilla Smilax glabra Roxb. (Liliaceae). J Agric Food Chem 52: 6091-6095, 2004.

11. Lu CL, Zhu W, Wang M, Xu XJ and Lu CJ: Antioxidant and anti-inflammatory activities of phenolic-enriched extracts of Smilax glabra. Evid Based Complement Alternat Med 2014: 910438, 2014

12. Jiang $\mathrm{J}$ and $\mathrm{Xu} \mathrm{Q}$ : Immunomodulatory activity of the aqueous extract from rhizome of Smilax glabra in the later phase of adjuvant-induced arthritis in rats. J Ethnopharmacol 85: 53-59, 2003.

13. Xia D, Fan Y, Zhang P, Fu Y, Ju M and Zhang X: Protective effects of the flavonoid-rich fraction from rhizomes of Smilax glabra Roxb. On carbon tetrachloride-induced hepatotoxicity in rats. J Membr Biol 246: 479-485, 2013.

14. Roubille C, Richer V, Starnino T, McCourt C, McFarlane A, Fleming P, Siu S, Kraft J, Lynde C, Pope J, et al: The effects of tumour necrosis factor inhibitors, methotrexate, non-steroidal anti-inflammatory drugs and corticosteroids on cardiovascular events in rheumatoid arthritis, psoriasis and psoriatic arthritis: A systematic review and meta-analysis. Ann Rheum Dis 74: 480-489, 2015.

15. Chen L, Yin Y, Yi H, Xu Q and Chen T: Simultaneous quantification of five major bioactive flavonoids in Rhizoma Smilacis Glabrae by high-performance liquid chromatography. J Pharm Biomed Anal 43: 1715-1720, 2007.

16. Shi L, Xu L, Yang Y, Song H, Pan H and Yin L: Suppressive effect of modified Simiaowan on experimental gouty arthritis: An in vivo and in vitro study. J Ethnopharmacol 150: 1038-1044, 2013.

17. Smith $\mathrm{CH}$ and Barker JN: Psoriasis and its management. BMJ 333: 380-384, 2006.

18. Wang Y: Clinical observation of combining traditional Chinese and western medicine treatment rheumatoid arthritis. J New Chin Med 47: 103-105, 2015.

19. Goldman ID and Matherly LH: The cellular pharmacology of methotrexate. Pharmacol Ther 28: 77-102, 1985.

20. Henderson GB: Folate-binding proteins. Annu Rev Nutr 10: 319-335, 1990.

21. de Graaf D, Sharma RC, Mechetner EB, Schimke RT and Roninson IB: P-glycoprotein confers methotrexate resistance in 3T6 cells with deficient carrier-mediated methotrexate uptake. Proc Natl Acad Sci USA 93: 1238-1242, 1996.

22. Masuda M, I'Izuka Y, Yamazaki M, Nishigaki R, Kato Y, Ni'inuma K, Suzuki H and Sugiyama Y: Methotrexate is excreted into the bile by canalicular multispecific organic anion transporter in rats. Cancer Res 57: 3506-3510, 1997.

23. Kusuhara $\mathrm{H}$ and Sugiyama Y: Role of transporters in the tissue-selective distribution and elimination of drugs: Transporters in the liver, small intestine, brain and kidney. J Control Release 78: 43-54, 2002.

24. Ranganathan P and McLeod HL: Methotrexate pharmacogenetics: The first step toward individualized therapy in rheumatoid arthritis. Arthritis Rheum 54: 1366-1377, 2006.

25. El-Sheikh AA, van den Heuvel JJ, Koenderink JB and Russel FG: Interaction of nonsteroidal anti-inflammatory drugs with multidrug resistance protein (MRP) 2/ABCC2- and MRP4/ABCC4-mediated methotrexate transport. J Pharmacol Exp Ther 320: 229-235, 2007.

26. Sweet DH, Bush KT and Nigam SK: The organic anion transporter family: From physiology to ontogeny and the clinic. Am J Physiol Renal Physiol 281: F197-F205, 2001. 
27. Sweet DH: Organic anion transporter (Slc22a) family members as mediators of toxicity. Toxicol Appl Pharmacol 204: 198-215, 2005.

28. Wang XD, Meng MX, Gao LB, Liu T, Xu Q and Zeng S: Permeation of astilbin and taxifolin in Caco-2 cell and their effects on the P-gp. Int J Pharm 378: 1-8, 2009.

29. Piskula MK: Factors affecting flavonoids absorption. Biofactors 12: $175-180,2000$

30. O'Leary KA, Day AJ, Needs PW, Mellon FA, O'Brien NM and Williamson G: Metabolism of quercetin-7- and quercetin-3-glucuronides by an in vitro hepatic model: The role of human beta-glucuronidase, sulfotransferase, catechol-O-methyltransferase and multi-resistant protein 2 (MRP2) in flavonoid metabolism. Biochem Pharmacol 65: 479-491, 2003.

31. Van Aubel RA, Masereeuw R and Russel FG: Molecular pharmacology of renal organic anion transporters. Am J Physiol Renal Physiol 279: F216-F232, 2000.

32. Hirohashi T, Suzuki H and Sugiyama Y: Characterization of the transport properties of cloned rat multidrug resistance-associated protein 3 (MRP3). J Biol Chem 274: 15181-15185, 1999

33. Wang M, Chen W, Wang Z, Lu C and Zhu W: HP-20 macroporous adsorption resin enrichment and purification of total flavonoids of glabrous greenbrier rhizome. Chin Tradit Patent Med 37: 2074-2078, 2015 (In Chinese).

34. Livak KJ and Schmittgen TD: Analysis of relative gene expression data using real-time quantitative PCR and the 2(-Delta Delta C(T)) method. Methods 25: 402-408, 2001.

35. Jacobs SA, Stoller RG, Chabner BA and Johns DG: 7-Hydroxymethotrexate as a urinary metabolite in human subjects and rhesus monkeys receiving high dose methotrexate. J Clin Invest 57: 534-538, 1976.

36. Kuijpers AL and van de Kerkhof PC: Risk-benefit assessment of methotrexate in the treatment of severe psoriasis. Am J Clin Dermatol 1: 27-39, 2000.

37. Oliverio VT and Zaharko DS: Tissue distribution of folate antagonists. Ann N Y Acad Sci 186: 387-399, 1971.

38. Scheufler E, Zetler G and Iven H: Pharmacokinetics and organ distribution of methotrexate in the rat. Pharmacology 23: 75-81, 1981.

39. Chinese Pharmacopoeia Commission: Pharmacopoeia of the People's Republic of China 2015. China Medical Science and Technology Press, Bejing, 2015 (In Chinese).

40. Chinese Pharmacopoeia Commission: Pharmacopoeia of the People's Republic of China, the First Division. China Medical Science and Technology Press, Bejing, 2010 (In Chinese).

41. Aquerreta I, Aldaz A, Giráldez J and Sierrasesúmaga L: Methotrexate pharmacokinetics and survival in osteosarcoma. Pediatr Blood Cancer 42: 52-58, 2004.

42. Chiang HM, Fang SH, Wen KC, Hsiu SL, Tsai SY, Hou YC, Chi YC and Chao PD: Life-threatening interaction between the root extract of Pueraria lobata and methotrexate in rats. Toxicol Appl Pharmacol 209: 263-268, 2005.
43. Zhao R, Liu L, Wang Y and Xiao Z: Vinegar-baked Radix Bupleuri modulates the cell membrane constituents and inhibits the P-gp activity in rat hepatocytes. BMC Complement Altern Med 14: 357, 2014

44. Zhao Y, Feng LM, Liu LJ, Zhang X and Zhao RZ: Clerosterol from vinegar-baked radix bupleuri modifies drug transport. Oncotarget 8: 21351-21361, 2017.

45. Takatori R, Takahashi KA, Tokunaga D, Hojo T, Fujioka M, Asano T, Hirata T, Kawahito Y, Satomi Y, Nishino H, et al: ABCB1 C3435T polymorphism influences methotrexate sensitivity in rheumatoid arthritis patients. Clin Exp Rheumatol 24: 546-554, 2006.

46. Bohanec Grabar P, Logar D, Lestan B and Dolzan V: Genetic determinants of methotrexate toxicity in rheumatoid arthritis patients: A study of polymorphisms affecting methotrexate transport and folate metabolism. Eur J Clin Pharmacol 64: 1057-1068, 2008.

47. Boušová I and Skálová L: Inhibition and induction of glutathione S-transferases by flavonoids: Possible pharmacological and toxicological consequences. Drug Metab Rev 44: 267-286, 2012.

48. Lin SP, Tsai SY, Hou YC and Chao PD: Glycyrrhizin and licorice significantly affect the pharmacokinetics of methotrexate in rats. J Agric Food Chem 57: 1854-1859, 2009.

49. Yang SY, Juang SH, Tsai SY, Chao PD and Hou YC: St. John's wort significantly increased the systemic exposure and toxicity of methotrexate in rats. Toxicol Appl Pharmacol 263: 39-43, 2012.

50. Hirota BC, Paula CD, de Oliveira VB, da Cunha JM, Schreiber AK, Ocampos FM, Barison A, Miguel OG and Miguel MD: Phytochemical and antinociceptive, anti-inflammatory, and antioxidant studies of Smilax larvata (Smilacaceae). Evid Based Complement Alternat Med 2016: 9894610, 2016.

51. She T, Zhao C, Feng J, Wang L, Qu L, Fang K, Cai S and Shou C: Sarsaparilla (Smilax glabra Rhizome) extract inhibits migration and invasion of cancer cells by suppressing TGF- $\beta 1$ pathway. PLoS One 10: $\mathrm{e} 0118287,2015$.

52. She T, Qu L, Wang L, Yang X, Xu S, Feng J, Gao Y, Zhao C, Han Y, Cai S and Shou C: Sarsaparilla (Smilax glabra Rhizome) extract inhibits cancer cell growth by $\mathrm{S}$ phase arrest, apoptosis, and autophagy via redox-dependent ERK1/2 pathway. Cancer Prev Res (Phila) 8: 464-474, 2015.

53. Samarakoon SR, Thabrew I, Galhena PB and Tennekoon KH: Modulation of apoptosis in human hepatocellular carcinoma (HepG2 cells) by a standardized herbal decoction of Nigella sativa seeds, Hemidesmus indicus roots and Smilax glabra rhizomes with anti- hepatocarcinogenic effects. BMC Complement Altern Med 12: 25, 2012

54. Ooi LS, Wong EY, Chiu LC, Sun SS and Ooi VE: Antiviral and anti-proliferative glycoproteins from the rhizome of Smilax glabra Roxb (Liliaceae). Am J Chin Med 36: 185-195, 2008. 